\title{
Bozouls - Château
}

\section{Christophe Saint-Pierre}

\section{(2) OpenEdition \\ Journals}

Édition électronique

URL : http://journals.openedition.org/adlfi/17224

ISSN : 2114-0502

Éditeur

Ministère de la culture

Référence électronique

Christophe Saint-Pierre, «Bozouls - Château », ADLFI. Archéologie de la France - Informations [En ligne], Midi-Pyrénées, mis en ligne le 03 mai 2016, consulté le 19 avril 2019. URL : http://

journals.openedition.org/adlfi/17224

Ce document a été généré automatiquement le 19 avril 2019

(c) Ministère de la Culture et de la Communication, CNRS 


\title{
Bozouls - Château
}

\author{
Christophe Saint-Pierre
}

Lien Atlas (MCC) :

http://atlas.patrimoines.culture.fr/atlas/trunk/index.php?

ap_theme=DOM_2.01.02\&ap_bbox $=2.647 ; 44.419 ; 2.782 ; 44.526$

1 Le service départemental d'archéologie du Conseil Général de l'Aveyron a effectué un diagnostic archéologique sur le territoire de la commune de Bozouls, en amont de l'aménagement d'une maison individuelle et sur prescription du SRA.

2 Localisé dans le périmètre supposé du château médiéval, et plus particulièrement contre le mur interprété comme le rempart de celui-ci, l'opération visait à évaluer la conservation d'éléments archéologiques pouvant attester de la présence de cet édifice et à proposer le cadre chronologique de son occupation.

3 Trois agents du service départemental accompagnés d'un topographe, et avec l'appui d'une entreprise de travaux publics locale, ont pratiqué un sondage perpendiculairement au long mur maçonné bien connu des habitants et des visiteurs. Ce sondage a permis aux archéologues d'appréhender le profil d'un fossé, de 4,50 m de largeur pour une profondeur de $1,50 \mathrm{~m}$ en moyenne, creusé parallèlement au rempart. La fortification repose directement sur la roche à l'aplomb du fossé. De multiples tessons de céramique, associés à des ossements d'animaux parfois brûlés, montrent que le fossé a servi de dépotoir avant son colmatage définitif. L'homogénéité de la céramique semble indiquer un entretien régulier du fossé sur le long terme mais une condamnation définitive dans un délai relativement bref autour du XIII ${ }^{\mathrm{e}} \mathrm{s}$. 


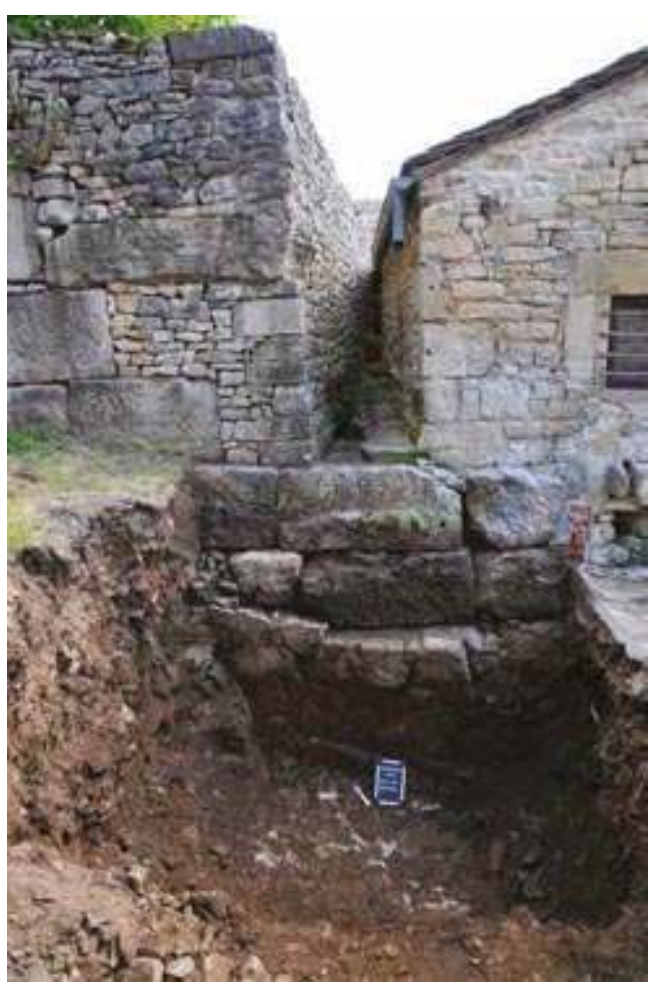

\section{Fig 01}

Détail de la paroi nord du fossé médiéval et de la semelle de fondation du mur antique SDA 12

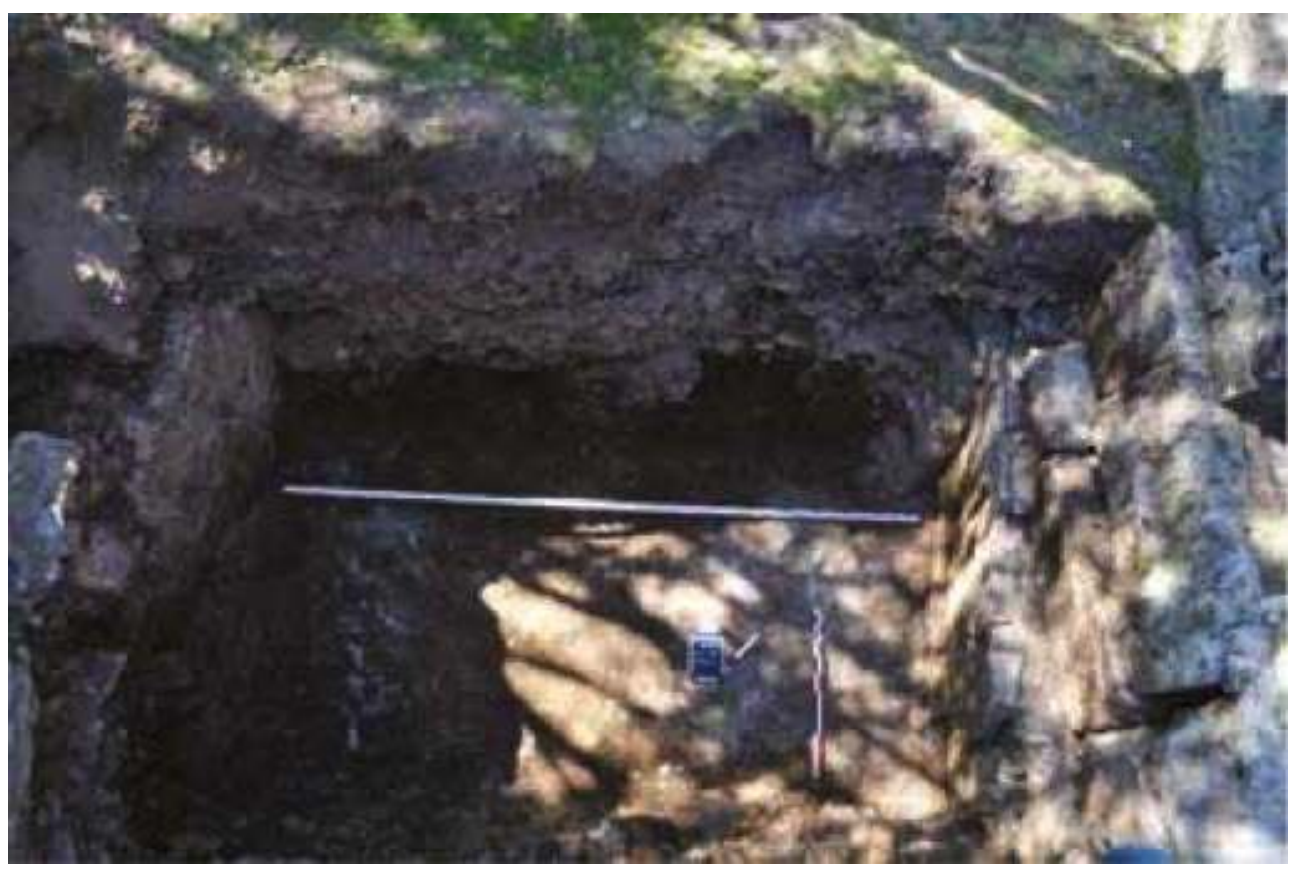

\section{Fig 02}

Vue zénithale du fossé médiéval

SDA 12 
4 Un autre intérêt de cette opération porte sur l'étude du monumental mur maçonné présent dans cette parcelle et interprété comme le mur du rempart médiéval protégeant et contrôlant l'accès au promontoire rocheux sur lequel se trouvaient le château et l'église Saint-Faust.

5 Si ce mur a effectivement bien joué un rôle dans la défense médiévale, son examen attentif suggère une origine plus ancienne, vraisemblablement gallo-romaine. Le développement de l'ouvrage, en appareil cyclopéen rectangulaire, est d'environ une trentaine de mètres. Il s'interrompt à ses deux extrémités bien avant la bordure du plateau, avec à l'extrémité nord-ouest un net retour d'angle difficilement compréhensible dans le cadre d'un rempart antique. En revanche, la base de l'appareil, munie d'une semelle débordante avec une feuillure de réglage sur sa face supérieure, est incontestablement en place. Il ne s'agit donc pas de blocs réemployés. Le tout n'est pas sans évoquer le soubassement d'un imposant monument antique se développant dans la parcelle contiguë plus au nord, vraisemblablement un temple monumental érigé au cœur du canyon de Bozouls. Des fouilles complémentaires sur la parcelle arrière de cette élévation seraient d'un grand intérêt pour l'histoire de Bozouls et permettraient de valider ces premières hypothèses.

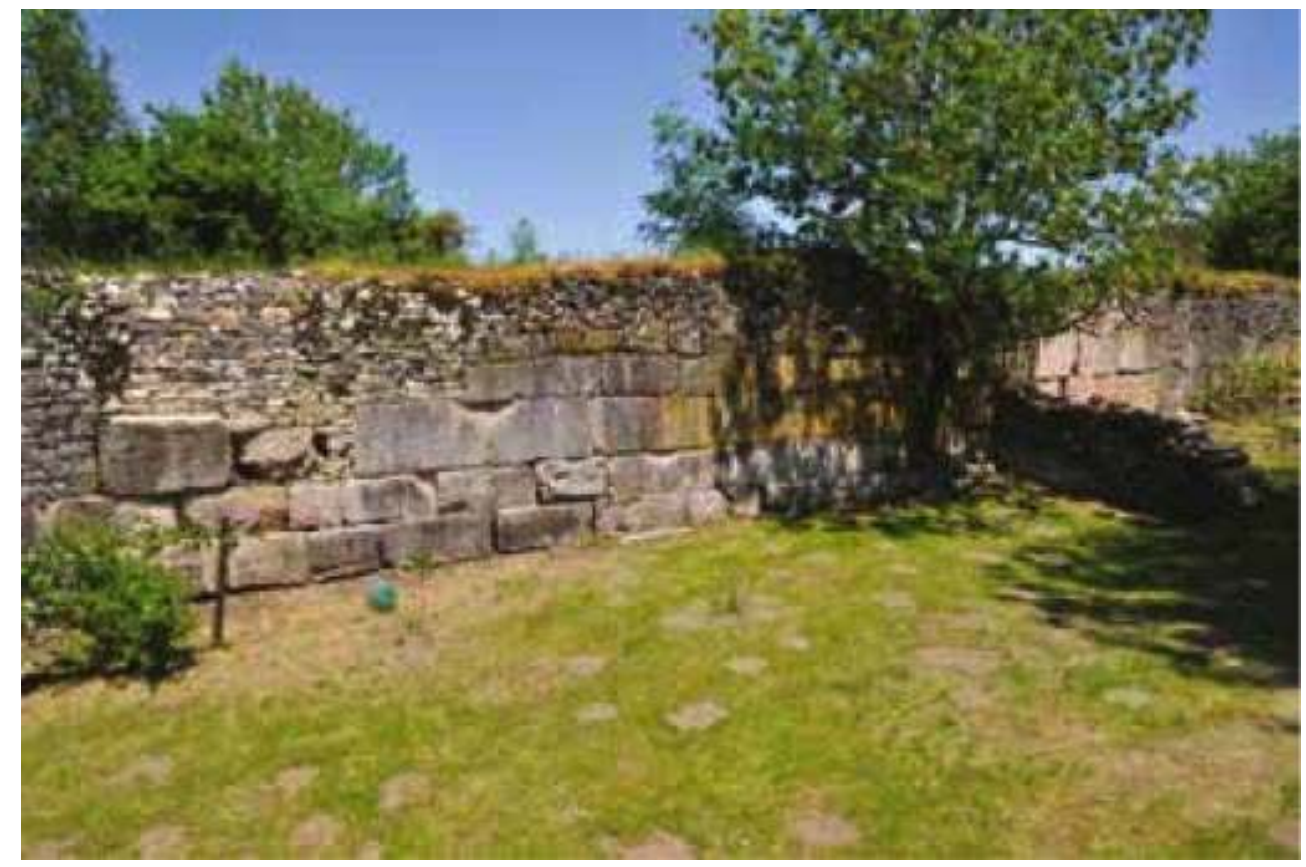

\section{Fig 03}

VUE gÉNÉRALE DE LA MAÇONNERIE ANTIQUE

SDA 12. 


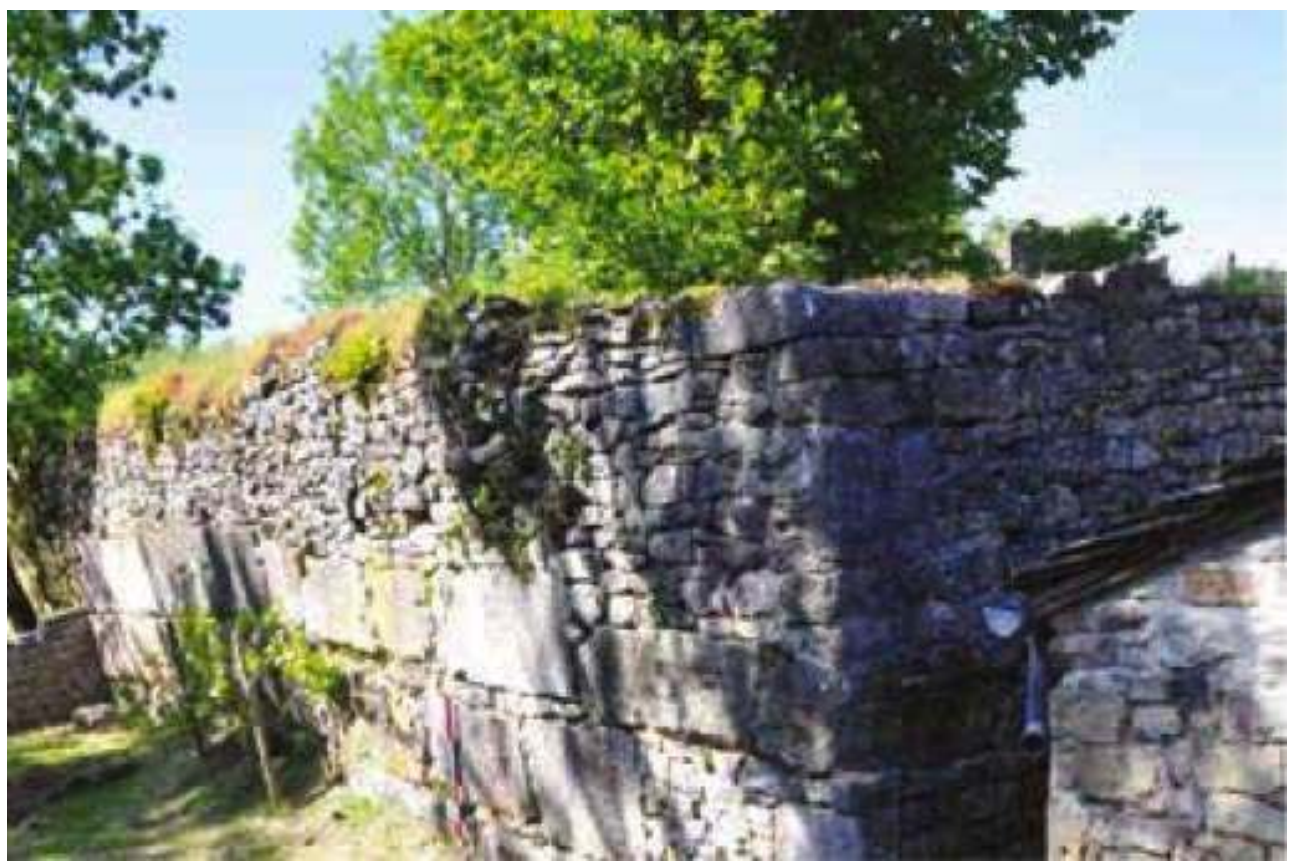

Fig 04

ARTICULATION DU FOSSÉ MÉdiÉVAL ET DE LA MAÇONNERIE ANTIQUE

SDA 12

\section{INDEX}

Mots-clés : fossé, mur, maçonnerie, céramique

Index géographique : Midi-Pyrénées, Aveyron (12), Bozouls

Index chronologique : Gallo-romain, Moyen Âge

operation Opération préventive de diagnostic (OPD)

\section{AUTEURS}

\section{CHRISTOPHE SAINT-PIERRE}

COL 12 